\title{
Adolescent and Young Adult Central Nervous System Tumor Survivors: Documentation of Late Effects Risks and Screening Recommendations in British Columbia
}

\author{
A. Fuchsia Howard ${ }^{1}$, Jordan Tran 1 , Avril Ullett², Michael McKenzie² ${ }^{2}$, Karen Goddard² \\ ${ }^{1}$ University of British Columbia, B.C., Canada, ${ }^{2}$ BC Cancer, B.C., Canada
}

\section{INTRODUCTION}

- Adolescent and young adult (AYA) (ages 15-39) survivors of a central nervous system (CNS) tumor are at high risk for late effects (LE).

- LE: treatment related health problems that occur more than 5 years after the end of therapy.

- AYA CNS cancer survivors are usually discharged to be followed in the community by their primary care provider.

- The information available to primary care providers to guide risk-based follow-up care remains unclear.

- Study objective: assess the documentation of LE risks and screening recommendations in the medical records of AYA CNS tumor survivors.

\section{METHODS \& MATERIALS}

Medical records of all AYA CNS tumor patients:

- Treated 1980-2010 with radiation therapy at BC Cancer

- Surviving 5 or more years after discharge, and alive

- LE documentation and screening recommendations extracted and analyzed descriptively.

\section{Patient Cancer Diagnoses ( $N=132$ )}

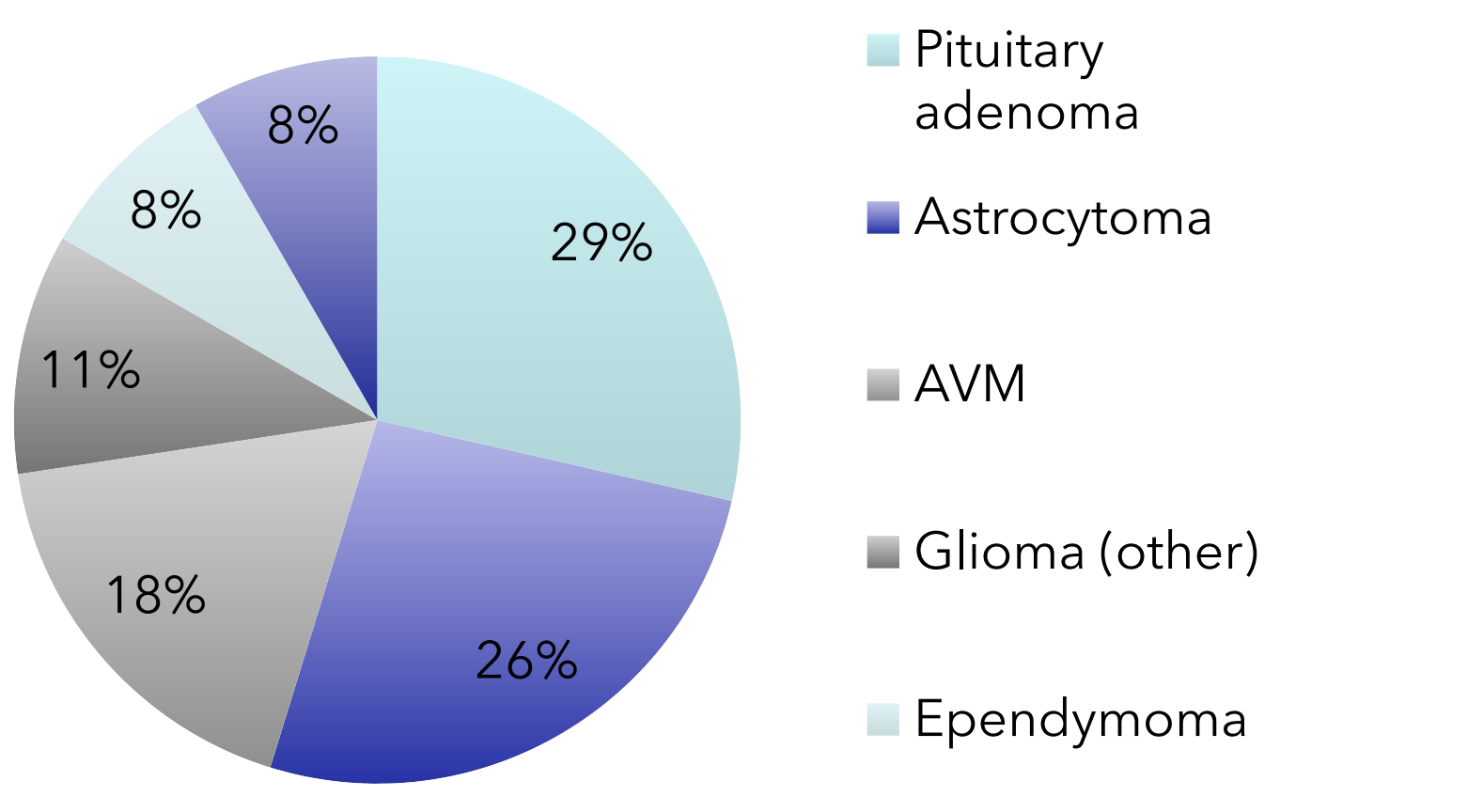

Patient Demographics and Treatment Data $(n=132)$

\begin{tabular}{|c|c|c|}
\hline & & $\%$ \\
\hline \multirow[t]{2}{*}{ Sex } & Male & 48 \\
\hline & Female & 52 \\
\hline \multirow[t]{4}{*}{ RT treatment } & Partial brain & 95 \\
\hline & Craniospinal axis & 10 \\
\hline & Partial spine & 8 \\
\hline & Whole brain & 4 \\
\hline \multirow[t]{7}{*}{ Chemotherapy } & & 17 \\
\hline & PCV & 7 \\
\hline & VP 16 & 4 \\
\hline & Temozolomide & 3 \\
\hline & Cisplatin/Carboplatin & 4 \\
\hline & Adriamycin & 2 \\
\hline & Cyclophosphamide & 1 \\
\hline \multirow[t]{2}{*}{ Discharge status } & Discharged with dictation & 50 \\
\hline & Lost to follow up & 50 \\
\hline
\end{tabular}
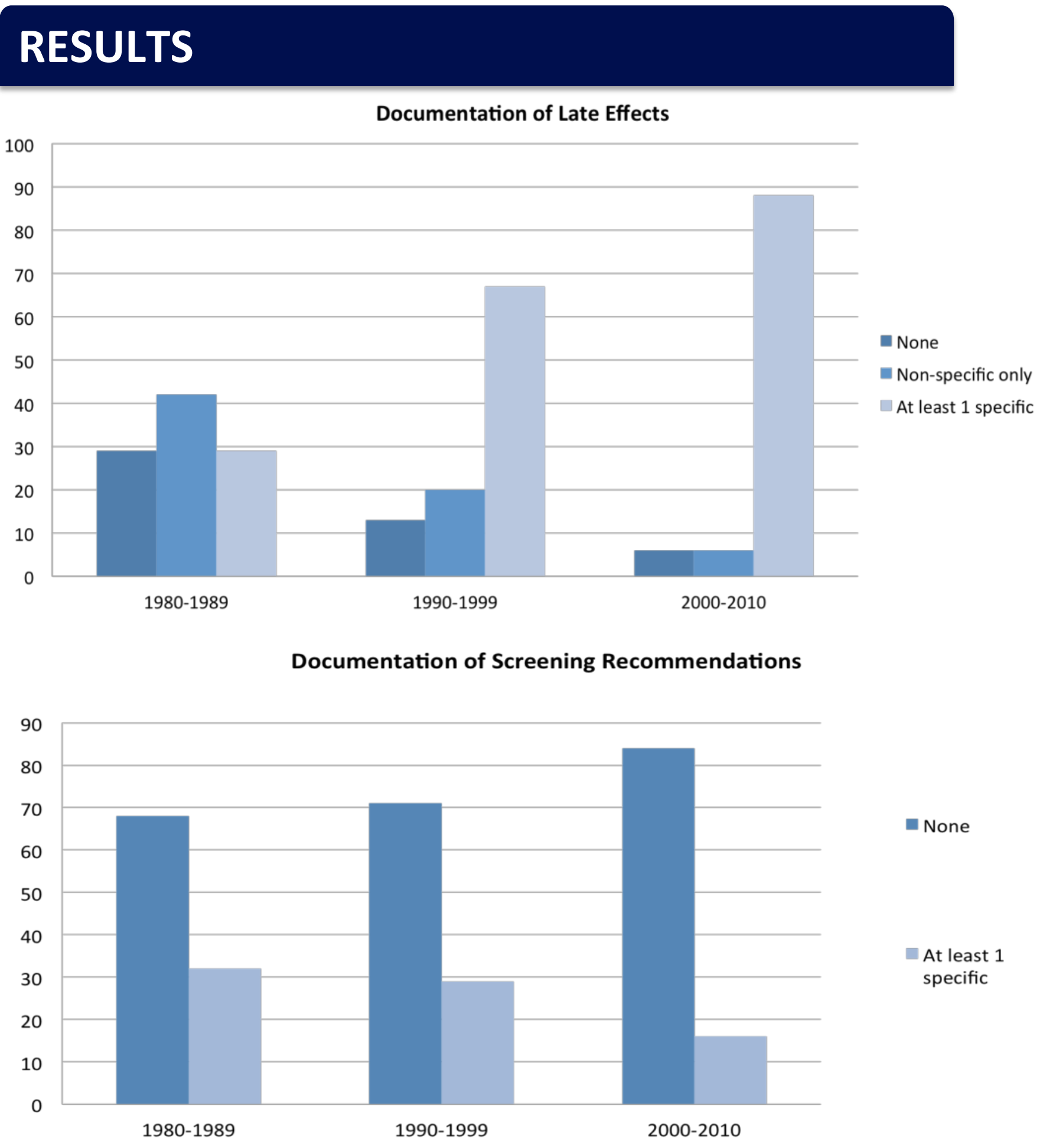

- Documentation of at least 1 specific LE risk increased over time $X^{2}(2$, $N=132)=32.257, p<.000$

- No documentation of a screening recommendation in $75 \%$ of charts

Most Commonly Specified Screening Recommendations ( $\mathrm{n}=\mathbf{5 4}$ instances)

\begin{tabular}{lcccc}
\hline & $\begin{array}{c}\text { Consult } \\
\%\end{array}$ & $\begin{array}{c}\text { Follow up } \\
\%\end{array}$ & $\begin{array}{c}\text { Discharge } \\
\%\end{array}$ & $\begin{array}{c}\text { Total } \\
\%\end{array}$ \\
\hline Pituitary & 11 & 17 & 7 & 35 \\
\hline Endocrine (general) & 6 & 7 & 13 & 26 \\
\hline Thyroid & 2 & 11 & 6 & 19 \\
Cholesterol & 0 & 4 & 0 & 4 \\
\hline Ophthalmology consult & 2 & 2 & 7 & 11 \\
Mammogram & 0 & 2 & 2 & 4 \\
\hline Secondary tumor CT & 0 & 0 & 2 & 2 \\
\hline Total & $\mathbf{2 0}$ & $\mathbf{4 3}$ & 37 & \\
\hline
\end{tabular}

\section{CONCLUSIONS}

- Half of patients were formally discharged from the BC Cancer.

- We found low rates of documentation of LEs risks in the charts of AYA CNS tumor survivors, though the documentation of at least one LE increased over time.

- All survivors were at high-risk for LEs, yet screening recommendations existed in only $25 \%$ of charts, and this documentation decreased over time.

- The creation of a standardized format for documentation that aligns with care processes specific to BC Cancer would improve communication with primary care providers. 